\title{
Planejamento e realização de oficina de capacitação de professores das escolas públicas para a inclusão do Tablet Educacional em sala de aula
}

\author{
Thiago G. Vasconcelos ${ }^{1}$, Flávia Veloso Costa Souza ${ }^{1}$, Ana Liz Souto O. de Araújo ${ }^{1}$, \\ Liviany R. Rodrigues ${ }^{1}$, Ítalo D. de Souza ${ }^{1}$, Alayse L. Sousa ${ }^{1}$ \\ ${ }^{1}$ Centro de Ciências Aplicadas e Educação - Universidade Federal da Paraíba (UFPB) - \\ Campus IV - Rua da Mangueira, S/N - Companhia de Tecido de Rio Tinto CEP 58.297- \\ 000 - Rio Tinto - PB - Brasil \\ \{thiago.gomes, flavia, analiz, liviany.reis, ítalo.souza, \\ alayse.lourenco\} @dcx.ufpb.br
}

\begin{abstract}
This paper reports the experiences in planning and conducting training workshop for public school teachers. The main objective of this action is to promote the inclusion of the tablet of education as a tool for educational support. The workshop was planned and performed in 6 sessions of two hours each, taught in two public schools. Initially the diagnosis of knowing the context of schools was conducted. At the end of the workshop, teachers teach classes using the functions of the tablet and the results were satisfactory. Educators consisted that when technologies are used specifically planned and contribute to more dynamic and engaging classes.
\end{abstract}

Resumo: Este trabalho relata as experiências vivenciadas durante o planejamento e a realização de oficina de capacitação para professores da rede pública. $O$ objetivo principal desta ação foi promover a inserção do Tablet Educacional como ferramenta de apoio educativo. A oficina foi planejada e executada em 6 encontros de 2 horas cada, ministrada em duas escolas públicas. Inicialmente foi realizado diagnóstico para conhecer o contexto das escolas. Ao final da oficina, os docentes ministraram aulas utilizando os recursos do tablet e os resultados foram satisfatórios. Os educadores constaram que quando as tecnologias são utilizadas de maneira direcionada e planejada contribuem para aulas mais dinâmicas e atrativas.

\section{Introdução}

As Tecnologias de Informação e Comunicação (TIC) têm sido inseridas na sala de aula como instrumentos que buscam motivar, estimular os alunos e apoiar os professores no uso de práticas pedagógicas dinâmicas e interativas. Valente (2008) ressalta que, o uso do computador possibilita a interação e a participação do aluno por sua condição chamativa. Ademais, a internet é um veículo de comunicação e interação, recheada de informações, de possibilidades e que, se utilizada adequadamente, pode ser uma fonte vasta de conteúdos que servirão de base para abrilhantar as discussões em sala de aula.

O Governo Federal do Brasil tem elaborado, através do Ministério da Educação, políticas que visam contribuir para o crescimento do uso de tecnologias educacionais digitais na rede pública de ensino. Os investimentos realizados pelo governo nos últimos anos têm a finalidade de melhorar a qualidade da educação do ensino público do Brasil, fornecendo aos professores recursos que possam melhorar as atividades de ensino. 
O Projeto Educação Digital - Política para computadores interativos e tablets faz parte de uma das ações desenvolvidas pelo Ministério da Educação para a inclusão das TIC no ambiente escolar. O projeto foi anunciado em fevereiro de $2012 \mathrm{com}$ a previsão de entregar 600 mil tablets para os professores do ensino médio das escolas públicas federais, estaduais e municipais. Segundo o portal do ministério da educação o investimento foi de aproximadamente $\mathrm{R} \$ 150$ milhões de reais (MEC, 2015). Além da entrega dos equipamentos, os professores receberam um curso de capacitação promovido pelo Programa Nacional de Tecnologia Educacional (ProInfo). Entretanto, mesmo após a realização do curso, os professores ainda apresentam dificuldades em utilizar o equipamento, principalmente relacionadas ao planejamento e execução de aulas.

O governo do Estado da Paraíba, em parceria com o Ministério da Educação, iniciou em fevereiro de 2013 o "Projeto Tablet Educacional" que previa a entrega de 26.400 tablets às escolas de ensino médio da rede estadual. Foram distribuídos pelo Governo do Estado 61.643 tablets educacionais, sendo 46.400 para os alunos do Ensino Médio e 15.243 para os professores (Ministério da Educação - PB).

Porém, é importante destacar que apenas a disponibilização dos equipamentos não é suficiente. Brito et al (2012) apontam que a formação dos professores apresenta lacunas no que se refere ao processo de inserção das TIC em sala de aula, mas que quando incentivados e capacitados, os professores mostram-se aptos à apropriação pedagógica e capazes de planejar suas aulas mais dinâmicas e diversificadas com as TIC. Em alguns casos, as formações oferecidas aos docentes para utilização e inserção das tecnologias não acompanham o professor nos primeiros usos em sala de aula. Dessa forma, as capacitações para inserção das TIC não conseguem preparar os mesmos para o desafio que seu uso em um ambiente escolar representa (Real et al, 2013). Bettega (2004) reforça destacando a importância da formação dos professores, apresentando a necessidade de desenvolver um processo de formação que articule prática, reflexão, investigação e conhecimentos teóricos a fim de promover mudanças na prática pedagógica.

Diante desse contexto, os acadêmicos do Curso de Licenciatura em Ciência da Computação, bolsistas do Programa Institucional de Bolsa de Incentivo à Docência PIBID buscaram iniciativas para colaborar com a inclusão do tablet educacional como instrumento de apoio para o desenvolvimento do ensino nas escolas conveniadas. Inicialmente, investigamos, por meio de questionários, como os professores concebem e utilizam as TIC nas atividades pedagógicas. Identificamos que os mesmos sentem dificuldades para inserir o tablet em sua prática pedagógica e que gostariam de participar de cursos que pudessem auxiliá-los no processo de inclusão do tablet educacional em sala de aula.

Diante do interesse dos docentes em participar de cursos, planejamos e executamos uma intervenção por meio de uma oficina de capacitação. Essa oficina teve o objetivo de apresentar aos professores as funcionalidades do tablet para o contexto escolar no intuito que eles adquirissem autonomia para usá-lo em sala de aula. A oficina contempla como atividade final o planejamento pedagógico e acompanhamento da aula prática do professor com o tablet. Para avaliação, analisamos qualitativamente os dados dos diários de bordo individual de cada participante da equipe e do questionário avaliativo aplicado aos professores.

\section{A capacitação dos docentes para inserção das TIC em sala de aula}

Desde a última década, dispositivos móveis, como tablet e smartphone, vêm ganhando espaço no contexto escolar. Segundo (Nichele, 2013, p.03), "a simplicidade e rapidez 
V Congresso Brasileiro de Informática na Educação (CBIE 2016)

Anais do XXII Workshop de Informática na Escola (WIE 2016)

para utilização, a interface amigável, e a facilidade para instalar os aplicativos (Apps) são aspectos que contribuem para a rápida aceitação e disseminação deste tipo de dispositivo".

Há uma grande variedade de aplicativos desenvolvidos e muitos apresentam potencial para uso em atividades de ensino e aprendizagem, em diferentes áreas e níveis de ensino. Nunes (2013) destaca a importância de integrar as TIC à educação urgentemente e isso ocorre devido a popularização da tecnologia e o aumento da utilização pela sociedade. Nunes afirma que os alunos, embora tenham contato intenso com a tecnologia, não conseguem aproveitar os recursos no contexto da educação, e por isso cabe aos docentes desenvolver estratégias pedagógicas que apoiem e incentivem a integração das TIC no processo de formação.

Para que os docentes promovam atividades com tablet ou outras ferramentas digitais, se faz necessário que os mesmos tenham fluência no uso das mídias, e estejam aptos para sua inserção em sala de aula. Diaz (2012 apud REAL, 2013, p.659) aponta para a inevitabilidade da capacitação dos professores sobre o uso das tecnologias, para que os mesmos possam explorar as funcionalidades e uso dos recursos no processo de ensino e aprendizagem.

O Núcleo de Tecnologia em Educação do Rio Grande do Sul (NTE/RS) realizou um conjunto de ações para apoiar a distribuição e incentivar o uso pedagógico dos tablets junto aos professores atuantes em sala de aula do ensino médio da rede pública estadual. A formação foi dividida em dois módulos de quatro horas, organizado da seguinte maneira: (i) O primeiro módulo apresenta características, recursos e informações gerais, explora o dispositivo para familiarização, com uso do equipamento e suas funcionalidades; (ii) O segundo módulo ofereceu aos professores uma formação em como usar o tablet como ferramenta pedagógica.

As observações referentes a essa formação são que alguns professores mostraramse entusiasmados em aprender como utilizar o tablet em sala de aula. Porém alguns professores apresentaram sentimentos contraditórios, "[...] queixas em torno das políticas públicas na educação e o tipo de investimentos aplicados; em relação as suas reais capacidades para utilizar a tecnologia [...] " (Real et al, 2013, p.664).

As formações oferecidas aos docentes para utilização e inserção das tecnologias, em muitos casos, não acompanham o professor nos primeiros usos em sala de aula. Para Real et al (2013), a tarefa de capacitar os docentes para utilizar as tecnologias, muitas vezes não conseguem preparar os mesmos para o desafio que seu uso, em um ambiente escolar, representa. $\mathrm{O}$ mesmo autor afirma que a formação continuada dos professores para uso dos tablets em sala, está comprometida em mostrar a necessidade de mudar o foco do processo do ensino para aprendizagem, ressaltando que docentes e discentes não são agentes antagônicos, mas parceiros na busca de soluções e construção de conhecimentos.

\section{Trabalhos relacionados}

Lima e Loureiro (2015) realizaram um estudo de caso no intuito de identificar a maneira como os licenciandos planejam usar TIC na docência. Os autores realizaram uma análise qualitativa em planos de aula desenvolvidos por licenciando dos cursos de Ciências Biológicas, Ciências Sociais, Educação Física, Letras (Português/Espanhol/Inglês), Física, História, Matemática, Pedagogia e Química. O estudo apontou que os licenciandos tendem a utilizar os recursos digitais centrados na ação do professor, pois apresentam dificuldades em utilizá-los no contexto educacional. 
Baptista e Vieira (2015) apresentam os resultados de uma pesquisa realizada em duas escolas públicas municipais, com o intuito de investigar de que forma as TIC favorecem a aprendizagem dos alunos nos projetos interdisciplinares. Concluíram que as tecnologias aliadas aos projetos interdisciplinares contribuem de forma significativa no processo de aprendizagem, possibilitando maior autonomia para os alunos.

Nicoleit et al (2014) descrevem o processo de formação continuada de professores do Município de Criciúma/SC. O objetivo do trabalho foi capacitar professores para uso das TIC, oferecendo subsídios teórico-metodológicos e práticos para a compreensão das possibilidades pedagógicas de sua utilização nas aulas. Durante a capacitação foram produzidos materiais que ofereceram suporte ao uso das TIC na sala de aula. Os resultados apontaram que os professores superaram as dificuldades e inquietações quanto à utilização de tecnologias e compartilharam experiências, saberes e práticas realizadas na sala de aula.

Nichele e Schlemmer (2013) identificaram aplicativos para tablet para o ensino da química com potencial de adoção pelas escolas brasileiras. Para selecionar os aplicativos relevantes, os autores criaram um modelo para contemplar informações essenciais no intuito de orientar o uso do aplicativo na disciplina. Como resultado, oito aplicativos foram avaliados e destacadas as potencialidades para o processo de ensino e aprendizagem em química.

\section{Planejamento da Oficina}

\subsection{Motivação para oferta da oficina}

A motivação para o desenvolvimento deste trabalho partiu dos dados obtidos a partir de questionário elaborado e aplicado aos professores nas escolas parceiras do projeto PIBID de Licenciatura em Ciência da Computação. O objetivo desse questionário foi identificar como os professores concebem e utilizam as Tecnologias de Informação e Comunicação nas atividades pedagógicas. O questionário era composto por 15 questões que buscavam identificar a formação acadêmica dos professores, a fluência em tecnologias, o uso das tecnologias em sala de aula e relatos de experiência sobre inserção das TIC em atividades pedagógicas.

A partir dos dados coletados identificamos que os professores e alunos haviam recebido o tablet educacional, mas não utilizavam. O questionário foi aplicado para 41 professores, sendo 25 professores da escola X e 16 professores da escola $\mathrm{Y}$. Todos os professores que responderam ao questionário possuíam o tablet educacional. Porém $24,4 \%$ desses professores relataram que o equipamento apresentou defeito com pouco tempo de uso, impossibilitando sua utilização. Em relação ao sistema, 36,6\% dos professores afirmaram que os dispositivos apresentavam problemas tais quais travar ou não permitir a instalação de novos aplicativos. Assim, 39\% dos professores afirmaram possuir o tablet educacional funcionando perfeitamente. O Gráfico 01 apresenta a situação dos tablets educacionais nas escolas. 
V Congresso Brasileiro de Informática na Educação (CBIE 2016)

Anais do XXII Workshop de Informática na Escola (WIE 2016)

Qual a situação do seu tablet educacional?

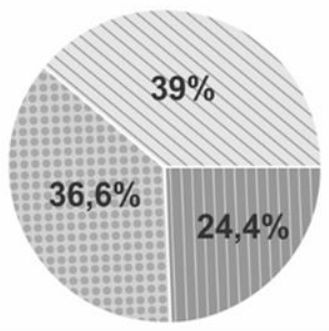

Apresentando defeito (10 Professores)

3 Funcionando com alguns problemas no sistema (15 Professores)

Funcionando perfeitamente (16 Professores)

\section{Gráfico 01. Situação dos tablets recebidos pelos professores}

No tocante à experiência dos professores em relação ao uso do tablet no processo de ensino e aprendizagem, 63,4\% dos docentes afirmaram nunca ter utilizado o equipamento em sala de aula. Os professores que já haviam utilizado o equipamento descreveram a experiência como satisfatória. Porém destacaram alguns problemas como distração dos alunos e a baixa velocidade de navegação da internet nas escolas, além da pouca fluência pessoal no uso dos equipamentos.

Em um segundo momento buscamos identificar os professores que teriam interesse em participar de uma oficina sobre o uso do tablet educacional em sala de aula e 38 professores demonstraram interesse.

\subsection{Planejamento geral da oficina}

A oficina foi planejada para a participação de no máximo cinco (05) professores em cada escola por turma, pois assim poderíamos acompanhar as atividades realizadas individualmente pelos professores durante a oficina. Os professores foram selecionados de acordo com seu horário e dia da semana disponível em comum. A oficina foi ofertada quatro vezes na escola $\mathrm{X}$ e três vezes na escola $\mathrm{Y}$.

$\mathrm{Na}$ etapa do planejamento, a oficina foi estruturada para ocorrer em seis encontros com duração de 2 horas cada, totalizando uma carga horária de 12 horas. O conteúdo planejado para cada encontro está resumido na tabela 1 . A oficina e o material foram elaborados buscando incentivar a autonomia no uso dos tablets pelos professores como recurso pedagógico em suas aulas.

Tabela 1 - Sumário da divisão dos conteúdos por encontro

\begin{tabular}{|l|l|}
\hline Encontro & \multicolumn{1}{|c|}{ Conteúdo planejado } \\
\hline 1 & $\begin{array}{l}\text { Possibilidades e exemplos de uso do tablet educacional em situações de ensino e } \\
\text { aprendizagem. Configurações básicas e menu configurações. }\end{array}$ \\
\hline 2 & $\begin{array}{l}\text { Transferências de arquivos via USB e Bluetooth, conexão Wi-Fi, gerenciamento de } \\
\text { pastas e arquivos. }\end{array}$ \\
\hline 3 & $\begin{array}{l}\text { Apresentação do Google Drive para compartilhamento de arquivos, criação de } \\
\text { documentos de texto, planilhas e apresentações. }\end{array}$ \\
\hline 4 & $\begin{array}{l}\text { Explorando Play Store, instalando e desinstalando aplicativos, apresentação de alguns } \\
\text { aplicativos úteis específicos por disciplina. }\end{array}$ \\
\hline 5 & $\begin{array}{l}\text { Apresentação de dicas de segurança, demonstração do aplicativo WPS Office. } \\
\text { Planejamento da aula prática de cada professor. }\end{array}$ \\
\hline 6 & Aula prática com a inserção do tablet (atividades pedagógicas) \\
\hline
\end{tabular}


V Congresso Brasileiro de Informática na Educação (CBIE 2016)

Anais do XXII Workshop de Informática na Escola (WIE 2016)

\section{Discussão dos Resultados}

Participaram da oficina professores das disciplinas de matemática, inglês, espanhol, geografia, história, português, biologia, educação física. Participaram 2 homens e 8 mulheres os quais apresentaram idade entre 27 e 59 anos. Eles possuíam o curso de licenciatura da respectiva disciplina que lecionam nas escolas. Os participantes mostraram-se motivados e engajados nas atividades realizadas durante a oficina. As oficinas ocorreram com um encontro semanal nas dependências das escolas.

No primeiro encontro, exibimos aos professores participantes dois vídeos ${ }^{1}$ que apresentavam a experiência do uso de tablets em outras escolas. Esses vídeos tiveram o objetivo de demonstrar que é possível utilizar o tablet educacional em sala de aula. Após os vídeos, realizamos uma dinâmica com os participantes com a finalidade de incentivar a reflexão sobre o uso dos tablets em sala de aula. Os professores acharam proveitoso refletir sobre as experiências que ocorreram em outras localidades. Eles reforçaram as dificuldades que existiam no contexto de cada uma das escolas, mas ao final concluíram que seria viável.

Nesse mesmo encontro iniciamos a apresentação das funcionalidades e configurações básicas. Observamos que os professores apresentavam dificuldades de uso do equipamento. Fornecemos acompanhamento individual e cada professor realizou a configuração dos seus tablets de acordo com suas preferências. Ao final, percebemos que estavam satisfeitos por terem conseguido configurar seus tablets.

No segundo encontro apresentamos as funcionalidades referentes a conectividade, destacando a transferência via USB, Bluetooth e conexão à internet via Wi-Fi. Notamos que havia certa insegurança por parte dos professores em realizar tais procedimentos, pois todas essas funcionalidades eram novas para os professores. Na conclusão do encontro, constatamos que já se sentiam seguros para realizar os procedimentos e ficaram satisfeitos com o resultado. Durante o encontro, propiciamos que cada professor conectasse seu equipamento ao projetor multimídia e transferisse arquivos utilizando Bluetooth.

No terceiro encontro exploramos as funcionalidades do Google Drive referentes a criação de novos documentos, apresentações e planilhas, assim também como o compartilhamento dos arquivos que foram criados no próprio aplicativo. Nessa aula, encontramos dificuldades. Com a demanda de muito processamento, o tablet não se mostrou eficaz no quesito hardware (processador e memória). Além disso, os professores não possuíam familiaridade de trabalhar com essa ferramenta e com arquivos compartilhados. Apesar das limitações de hardware do tablet, os professores conseguiram realizar as atividades que foram solicitadas, e se sentiram animados com a fluência e as possibilidades de uso dessa ferramenta em sala.

No quarto encontro apresentamos aplicativos que poderiam ser utilizados por cada docente em sua disciplina. Os aplicativos foram selecionados de acordo com a área de atuação dos docentes. Demonstramos o processo de localização e instalação do aplicativo na Play Store, as características gerais de cada aplicativo e as possíveis ideias de utilização em sala de aula. Em seguida, os professores testaram os aplicativos em seus tablets para decidir qual(is) seria(am) utilizado em aula. Notamos que os professores sentiram-se motivados, entretanto a insegurança no uso dos aplicativos em sala foi notável.

No quinto encontro, inicialmente abordamos dicas de segurança em relação ao tablet educacional, uso de antivírus e limpeza de cache. Em seguida, trabalhamos o aplicativo WPS Office no qual permitiu aos professores o conhecimento de mais uma ferramenta para o planejamento pedagógico de suas aulas. Por fim, iniciamos o 
planejamento de uma aula a ser ministrada pelo professor com inserção do tablet. A aula planejada deveria abordar um assunto da disciplina em que o docente atua e utilizar o tablet como ferramenta pedagógica. Nesse momento, escolhemos os aplicativos os quais possuíssem relação com conteúdos futuros das disciplinas, que fossem relevantes e que executassem adequadamente aos requisitos de hardware do tablet. Após as escolhas de cada professor, eles demonstraram estar mais confiantes em usar os aplicativos escolhidos com seus alunos.

No sexto encontro realizamos a aula prática, onde o professor teve a oportunidade de utilizar o tablet como recurso de apoio pedagógico na sua aula com o apoio presencial da nossa equipe. A turma foi dividida em grupos para facilitar a supervisão e devido alguns alunos não possuírem o equipamento. Todavia, alguns alunos que não estavam com o tablet educacional fornecido pelo Governo, utilizaram os próprios dispositivos (como celulares e tablet pessoal) para desenvolver a atividade. Os aplicativos foram instalados na própria escola através da rede wi-fi. Todos os professores participantes da oficina realizaram a aula prática. A seguir, destacaremos duas aulas práticas: a de matemática e geografia.

A seguir serão apresentados os resultados de duas aulas que ocorreram, uma na escola X e outra na escola Y.

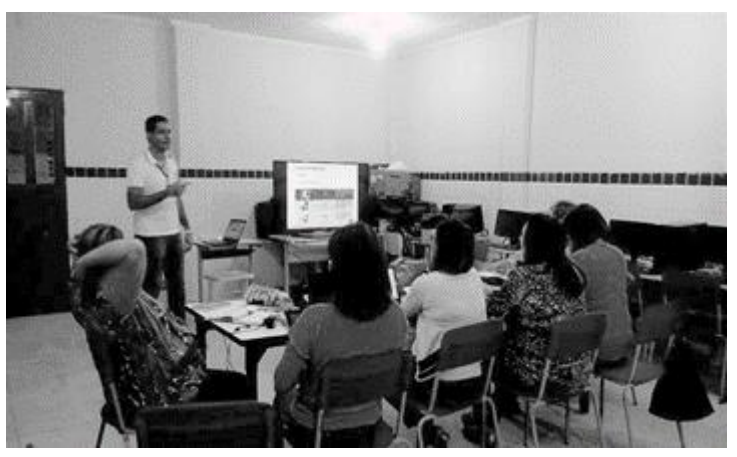

Figura 1. Quinto encontro na escola X

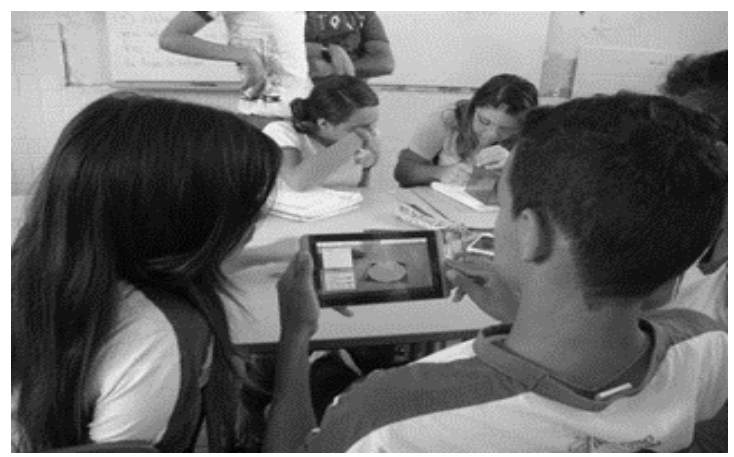

Figura 2. Sexto encontro na escola $Y$

\section{1 - Aula de geografia com tablet}

Na escola X, o professor de geografia optou por utilizar os aplicativos Google Earth, Google Maps e Street View. Aula teve o objetivo trabalhar o conteúdo de localização geográfica. Os alunos tinham que localizar pontos determinados pelo professor. Os alunos iniciaram a aula com o Google Earth, obtendo a vista aérea da terra, visualizando assim os oceanos e continentes, onde localizariam a América do Sul. Após isso, usaram o Google Maps para localizar a cidade em que residem e posteriormente usaram o Street View para visualizarem suas residências. Os alunos demonstraram bastante entusiasmo durante a realização da atividade. Da mesma forma o professor, que considerou a realização da aula como sendo de grande importância para a aquisição de novos conhecimentos e o uso da tecnologia em sala de aula.

\section{2 - Aula de matemática com tablet}

Na escola Y, a aula prática de matemática com a utilização do tablet educacional foi desenvolvida com a utilização de dois aplicativos: MathWay e o Geometry101. O professor escolheu os aplicativos devido os mesmos possuírem relação com os assuntos programados. A aula teve como tema cálculo geométrico e o objetivo foi proporcionar aos alunos atividade de fixação do assunto. Assim, o professor elaborou uma atividade 
no quadro para que os alunos respondessem em sala. Durante a realização da atividade, os alunos utilizavam o aplicativo MathWay para verificar se suas respostas estavam corretas. Já o aplicativo Geometry101 foi utilizado para visualização dos polígonos em 3D em várias dimensões. Como resultado, a utilização dos aplicativos proporcionaram maior dinamismo na aula.

\section{Avaliação da Oficina e Lições Aprendidas}

Durante e após a realização dos encontros, cada membro da equipe utilizou o diário de bordo para registrar as atividades e sua percepção sobre os acontecimentos que ocorreram durante os encontros. Todos registraram a dificuldade que os professores demonstravam de manusear o tablet e a insegurança caso o aplicativo selecionado para a aula prática não funcionasse conforme o esperado.

Ao final da oficina, os professores responderam um questionário avaliativo que abordava questões relativas à duração da oficina, aos materiais e recursos utilizados, aos membros da equipe responsáveis por ministrar as aulas, bem como sugestões de melhorias para uma futura oficina. A partir dos dados obtidos, os docentes afirmaram que a oficina cumpriu os objetivos propostos, e mostraram-se interessados em dar continuidade ao acompanhamento pedagógico das atividades pela equipe em sala de aula. Sugeriram que a carga horária da oficina fosse maior. Supomos que o pedido de maior carga horária seja devido a insegurança pessoal e a vontade de ser orientado por mais tempo no manuseio com o tablet.

A partir da aplicação dos questionários e das observações registradas no diário de bordo identificamos pontos positivos e negativos. Como pontos positivos, destacamos o empenho e a motivação dos professores em relação ao uso do tablet e o interesse em planejar uma atividade para aplicar junto aos seus alunos. Mesmo com as limitações, nenhum professor desistiu durante a oficina. Além disso, o bom humor e a vontade de superação de cada professor foi fundamental para mitigar as dificuldades.

Como pontos negativos destacamos a dificuldade de horários disponíveis em comum para realização da oficina por parte dos professores. Todos eles trabalham em mais de uma escola e ministram aula nos três turnos. A qualidade da internet nas escolas foi outro ponto que atrapalhou a utilização dos aplicativos. E por último, destacamos que a maioria dos tablets dos alunos das escolas estarem quebrados ou em mal funcionamento.

\section{Considerações Finais}

Considerando o contexto de inserção das TIC na sala de aula, este trabalho relatou uma experiência de oficina de capacitação para professores da rede pública sobre o uso dos tablets educacionais. Primeiro realizamos um diagnóstico sobre o estado atual da inserção das TIC nas escolas, com destaque aos tablets educacionais concedidos pelo Governo do Estado. Em seguida, elaboramos uma oficina de capacitação que ao final, permitisse planejar e acompanhar os professores em sua primeira aula prática com os tablets em suas respectivas disciplinas lecionadas.

Como resultados, constatamos que apesar das dificuldades dos professores em usar os tablets, o desejo de aprender e de proporcionar aos alunos novas práticas pedagógicas, foi fundamental para o progresso da oficina. $\mathrm{O}$ momento inicial de reflexão sobre o porquê e o para quê utilizar os tablets, além dos exemplos de sucesso de outras localidades, contribuíram para despertar nos professores o desejo de saber como utilizar o tablet educacional em suas aulas. Conseguimos que os professores participantes da 
V Congresso Brasileiro de Informática na Educação (CBIE 2016)

Anais do XXII Workshop de Informática na Escola (WIE 2016)

oficina utilizassem os tablets em sala de aula com seus alunos, sendo assim uma experiência nova e motivadora.

A participação no treinamento proporcionou a nós, licenciandos em Computação, uma rica experiência profissional. Vivenciamos a realidade das escolas públicas de nossa região, suas dificuldades tanto materiais, quanto físicas, e conseguimos mitigar essas limitações e realizarmos o trabalho proposto. Além disso, contribuímos com as escolas participantes, favorecendo a inserção das TIC em sala de aula, haja vista que alguns docentes não sabiam como ou mostravam-se apreensivos em utilizar tais tecnologias como ferramenta de apoio ao processo de ensino e aprendizagem. Com a oficina foi possível demonstrar vantagens que essa nova abordagem pode proporcionar, para que as aulas sejam mais interativas e dinâmicas.

Como trabalho futuro, planejamos continuar o acompanhamento dos professores dessa primeira turma em outras aulas práticas. Também iremos reformular $o$ planejamento da oficina e ofertar novas turmas, de acordo com a disponibilidade dos professores.

\section{Agradecimentos}

Os autores agradecem à CAPES pela concessão de bolsas do Programa Institucional de Bolsa de Iniciação à Docência - PIBID no período de realização desta pesquisa.

\section{Referencias}

Baptista, B. T.; \& Vieira, M. F. (2015). “A utilização das Tecnologias da Informação e Comunicação nos projetos educacionais interdisciplinares" In: Anais do XXI Workshop de Informática na Escola.

Bettega, M. H. Educação continuada na era digital. São Paulo: Cortez, 2004, p. 50-51.

Brito, G. S, et al. A Inserção de Tecnologias na Prática Docente: Fazendo o mesmo de Forma Diferente. IX ANPED Sul, Seminário de Pesquisa em Educação da Região Sul, 2012 .

Lima, L., \& Loureiro, R. (2015). “A integração entre Docência e Tecnologias Digitais da Informação e Comunicação na Formação de Licenciandos”. In: Anais do Workshop de Informática na Escola. Vol. 21, No. 1, p. 395.

Nichele, A. G.; Schlemmer, E. (2013). "Tablet no Ensino de Química nas Escolas Brasileiras: Investigação e Avaliação de Aplicativos. " In: III Colóquio LusoBrasileiro de Educação a Distância e Elearning, 1-15.

Nicoleit, E. R.; Giacomazzo, G. F., \& Gonçalves, L. L. (2014). "Formação de Professores da Rede Municipal de Educação para o uso de TIC: um relato da experiência de Criciúma/SC". In: Anais do Workshop de Informática na Escola. Vol. 20, No. 1, p. 615 .

Nunes, V. (2013). "Projeto Tablet em Sala de Aula: Uma Proposta de Inovação Acadêmica", In: Anais $5^{\circ}$ Simpósio Hipertexto e Tecnologia na Educação, $1^{\circ}$ Colóquio Internacional de Educação com Tecnologias.

Portal do Governo do Estado da Paraíba. (2015). "Proinfo Realiza Seminario de Encerramento dos Projetos UCA e Tablet Educacional", 
V Congresso Brasileiro de Informática na Educação (CBIE 2016)

Anais do XXII Workshop de Informática na Escola (WIE 2016)

http://www.paraiba.pb.gov.br/secretarias/educacao/proinfo-realiza-seminario-deencerramento-dos-projetos-uca-e-tablet-educacional, Fevereiro.

Portal MEC. (2015) "Ministerio Distribuirá Tablets a Professores do Ensino Médio", http://portal.mec.gov.br/index.php?option=com_content\&view=article\&id=17479:mi nisterio-distribuira-tablets-a-professores-do-ensino-medio\&catid=215, Fevereiro.

Portal MEC. (2015) “Ministerio Entrega Tablets para Iniciar Formação de Professores do Ensino Médio", http://portal.mec.gov.br/index.php?option=com_content\&view=article\&id=18241:mi nistro-entrega-tablets-para-iniciar-formacao-de-professor-do-ensinomedio\&catid=372:agenda, Fevereiro.

Real, L. M. C.; Tavares, M. N. R.; Picetti, J. S. (2013). "Formação de Professores para o Uso Educacional de Tablets no Ensino Médio: possíveis mudanças na prática pedagógica", In: Anais dos Workshops do Congresso Brasileiro de Informática na Educação.

Valente, J.A. (2008). “Aprendizagem continuada ao longo da vida o exemplo da terceira idade". In: Salgado, Maria Umbelina Caiafa. Amaral, Ana Lúcia. "Tecnologias da educação: ensinando e aprendendo com as TICs". MEC/SEED. 